\title{
Analogous Electrical Model of Water Processing Plant as a Tool to Study "The Real Problem" of Process Control.
}

\author{
Ani Vincent Anayochukwu \\ Department of Electronic Engineering, University of Nigeria, Nsukka. Enugu State. \\ Nigeria. \\ vincent_ani@yahoo.com \\ $+2348054024629$
}

\begin{abstract}
This paper presents an analogous electrical model for water processing plant. The three major components of the plant; the connecting pipes, the water tanks and the filter have been modeled here by resistors, capacitors and inductors of an electrical circuit as a model of the plant. The mechanical properties of these components are thus represented by equivalent electrical properties as resistance, capacitance and inductance, respectively. In these representations the resistance is expressed as a function of both the cross sectional area (A) and the length (L) of the pipes; and the capacitance is expressed as a function of the Area of the tanks (capacity of tank), while the inductance (constriction to debris) is expressed as a function of number of wound string on the filter cartridge. From the results of the simulation, it was observed that by varying the electrical parameters (resistors, capacitors, inductor), it is possible to study the way the manipulation of equivalent parameters of the analogous mechanical components (the connecting pipes, the water tanks and the water filter) of the water plant could influence the rate of water flow in the production process. This work does demonstrate the possibility of knowing from the beginning the various sizes of pipes, tanks and filter to be used and how these will affect the flow of water in the plant before going into the physical construction of the plant. This method could be used in a more complex system.
\end{abstract}

\section{Keywords}

Analogous System, State equation, Process Control, modeling, Simulation, Nigeria.

\section{INTRODUCTION}

Process control research is a term that is often used but rarely defined. The basic concept of process control obviously takes on a meaning that reflects the nature of its application. In spite of the diverse meaning associated with the term "process control," there is one rather basic idea that tends to apply to all research situations. Process control research is the application of scientific principles and methods to the study of the over-all system behaviour of the process.

Process control is a unique part of industrial production that deals with the control of variables that in some way influence materials and equipment during the production of a product. In this paper, it is the assessment of the rate of water flow through a water processing plant. Proper

DOI : 10.5121/ijctcm.2013.3101 
process control for a bottled water production plant is concerned primarily with the control of rate of water flow through the plant using modeling techniques. Process control model can be used in the design of water treatment plants and prediction of treatment efficiency. It can also be used in assessing the nature of flow through the plant.

The application of control theory has essentially two phases:

\subsection{Dynamic analysis and Control system design.}

The analysis phase is concerned with determination of the response of a plant to commands, disturbances, and changes in the plant parameters.

If the dynamic response is satisfactory, there need be no second phase. If the response is unsatisfactory and modification of the plant is unacceptable, a design phase is necessary to select the control elements (the controller) needed to improve the dynamic performance to acceptable levels [1]. Control theory itself has two categories:

\subsubsection{Classical and Modern Control Theory.}

Classical control theory, which had its start during World War II, can be characterized by the transfer function concept with analysis and design principally in the Laplace and Frequency domains.

Modern control theory has arisen with the advent of high-speed digital computers and can be characterized by the state variables concept with emphasis on matrix algebra and with analysis and design principally in the time domain. Modem control theory deals with the analysis and synthesis of systems and devices for the control of complex multi-input multi-output systems. It involves the application of mathematical techniques to analyze, synthesize, and optimize devices for the control of a wide variety of systems. Modern control theory, despite its apparent mathematical complexity, provides a unified approach to solving a wide variety of guidance and control analysis, design, and optimization problems. The application of modern control theory to the development of tactical guided weapons is a high interest, high potential technology.

Modem control theory is based on abstract mathematical concepts and its development uses a system of notation and terminology largely incomprehensible to engineers and managers not skilled in the art. As a body of knowledge, modern control theory encompasses all of classical control system design, augmented with computational techniques largely developed over the past two decades. Although these techniques are highly mathematical in nature, a knowledge of their general approaches and some familiarity with their results is necessary to appreciate and comprehend their intended applications.

A key notion in modem control theory is the use of a state variable model for the dynamic system. The use of state variable methods has been all pervasive during the last two decades. The state variables of a dynamic system are the smallest set of numbers which define the values of all variables of interest relating to a dynamic system or mathematical model at a particular point in time or space. State variable models are commonly applied in modern control theory to represent dynamic systems and their components. The state variable technique is applicable to systems described by linear or nonlinear continuous-time differential equations or discrete-time difference equations. The main reason for the use of the state variable technique is that it permits the use of matrix algebra and vector notation, resulting in highly compact mathematical descriptions of modern control problems. 
Modern Control theory can be used in

- Flight Control Systems, eg Modern commercial and military aircraft, Autoland systems, and unmanned aerial vehicles (UAVs).

- Robotics, it can be used to study and design High accuracy positioning for flexible manufacturing and Remote environments: space, sea, non-invasive surgery, etc.

- Chemical Process Control, modern control theory can be used to the Regulation of flow rates, temperature, concentrations, etc. Can be used also in Long time scales, but only crude models of process

- Heating Ventilation and Air Conditioning (HVAC) as Basic thermostatic controls to building level systems.

- Automotive; it can be used to design Engine control, transmission control, cruise control, climate control, etc

\subsection{The underlying Control Theory.}

Control systems have played, and are still playing a role of ever increasing importance in our personal and industrial lives. This cannot be more evident than the areas they cover: from timekeeping to transportation, and from pure mathematics to business and profit. The impact of control on our daily lives is ubiquitous. Our homes are replete with control systems. They govern water closet, water heater, refrigerators, washing machines, audio and video equipment, etc. The subject of automatic controls is enormous, covering the control of variables such as temperature, pressure, flow, level, and speed. Process control covers an area ranging from the control of a simple domestic cooker to a complete production system or process, as may be found in a large petrochemical complex [2].

Factories and processing plants cannot function without control systems. Control system has played a vital role in the advance of engineering and science and has become an important and integral part of modern manufacturing and industrial processes. In the processing industry, controllers play a crucial role in keeping our plants running; virtually everything from simply filling up a storage tank to complex separation processes and chemical reactors [3]. Control systems are found in abundance in all sectors of industry such as process control and quality control of manufacture of products, automatic assembly line tool control, space technology and weapon systems, computer control, transportation systems, power systems, robotics and many others. Control theory is very useful in technological applications, and is meeting an increasing use in field such Economics and Sociology. Even such problems as inventory control and social and economic systems control may be approached from the theory of control systems.

\subsection{The Control Problem.}

Over the years, man has constantly searched for reliable methods of controlling things around him to suit his purpose. The successful operation of a system under changing conditions often requires a control system. The flow of water in a Production Plant was previously monitored by having an operator take a pressure reading in the treatment plant once or twice a day. Obviously, this daily routine was wasteful and hardly accurate. It was impossible to maintain a stable flow even with nearly continuous operator intervention. The correct amount of water needed to bottle or sachet was very difficult, if not impossible, to ascertain from a pressure reading and thus overshooting of desired flow was common [4]. 
Bottle or sachet water plants without process control are likely to experience problem such as the water level in the filter cells in the tanks tend to fluctuate widely and create the potential for partial drainage, overflow, and potential initial turbidity breakthrough at the beginning of the filtration cycles thereby causes most of the products not to fill properly.

\subsection{Analogous Systems}

Use of the electric analog model in fluid flow is possible because of the mathematical similarity between the flow of electricity in conducting materials and the flow of fluid in porous media [5], [6], [7].

Electric analog methods are now regarded as one of the powerful computing tools available to the hydrologist. Direct simulation of the hydrologic system by electrical methods simplifies the computational process. Once the analog model is verified through the use of field data, all electrical phenomena observed on the model can be directly related to hydrologic factors. Any theoretical set of water flow conditions, including alternative solutions, can be modeled, and the effects observed [8].

The electrical conductivity of the resistors is proportional to the hydraulic conductivity of the plant, and the electrical capacitance is directly related to the storage coefficient of the plant. A resistor impedes the flow of electricity in the same way as the piping materials impede the flow of water through the plant; likewise, capacitor stores electricity in a manner similar to the way water is stored in a tank.

If such a model is quantified, the electrical units of potential, charge, current, and model time correspond to the hydraulic units of head, volume, flow rate, and real time. The concept of analogous system is a very useful and powerful technique for system modeling [9].

To develop fully an analog model requires detailed analysis of the process parameters. The flow system under equilibrium or steady-state conditions (before development) is described by a form of law of conservation of mass (fluid flow continuity),

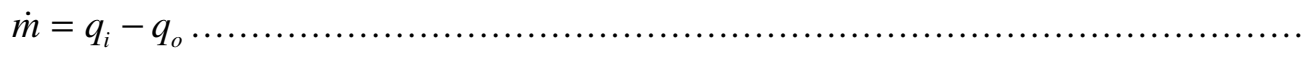

This simply states that the time rate of change $\dot{m}$ of mass in a container must equal the total mass inflow rate minus the total outflow rate. The quantity of water moving into the plant (recharge) is about equal to the quantity of water moving out of the plant (discharge). Water levels in the plant are a function of the magnitude of inflow and outflow and the characteristics of the materials through which the water is moving.

In liquid flow system, the differential equation describing liquid flow is derived by law of conservation of mass.

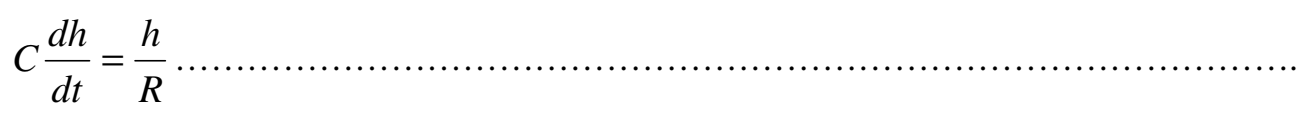

Where

$C=$ storage coefficient (dimensionless) 
$\frac{d h}{d t}=$ change in water level with time, in

metre per seconds.

$h=$ water level, in metre

$R=$ restriction in piping

$t=$ time in hours

The equivalent equation for field in electricity is derived by Kirchhoff's voltage and current laws

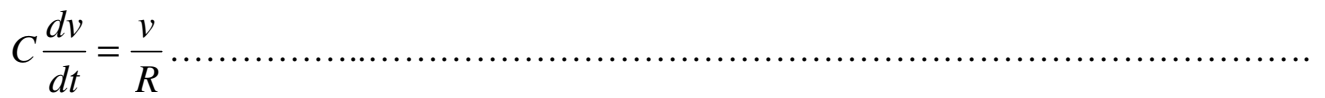

Where

$C=$ electrical capacitance, in farads

$\frac{d v}{d t}=$ change in voltage with time

$t=$ time, in seconds

$R=$ electrical resistance, in ohms

$v=$ electrical potential, in volts

The similarity between these two equations indicates that the cause-and-effect response in a hydrologic system can be duplicated in an electrical system, provided the two are dimensionally equivalent [8]. Mathematically, a solution to the response of developed plant requires use of equations that are too complex for ordinary solution. However, an electric analog model can be constructed that closely approximates the actual flow system because the flow of fluid through porous media is analogous to the flow of current through conducting material.

A model that is quantitatively proportional to the liquid flow system (flow system) can be built by selecting proper electrical components. Again, comparison of these two equations shows that the behaviour of the two systems is determined by the same basic differential equation. The systems are analogous and there is a one-one correspondence between the elements of the two systems. The analogy is very close. The effect of variations in L, C and R on the water-levels in the hydraulic system can thus be determined by simply observing the effect on the voltages in the electric circuit of variation in $\mathrm{L}, \mathrm{C}$ and $\mathrm{R}$. The voltage across the capacitor and the current in the circuit vary in the same way as the water-Level and velocity of the mass [10]. In complex waterflow systems, it is impractical to measure all these parameters in great detail or with high accuracy. If, however, they are known approximately, initial tests can be made with an analog model. Usually model response on the first few trails bears little resemblance to actual water-level changes. Through evaluation of model response and reconsideration of the original plant parameters, the model design is revised until the water-level change computed by the model agrees with observed changes [8]. 
However, electrical analogies have the advantage that they can be set up very easily in the laboratory. A change in a particular parameter can be accomplished very easily in the electric circuit to determine its overall effects and the electric circuit can be approximately adjusted for the desired response. Afterwards, the parameters in the liquid level system can be adjusted by an analogous amount to obtain the same desired response [11].

From figure 1, the Liquid - Levels, $h_{1}, h_{2}$, and $h_{3}$ of the flow system are directly analogous to the node voltages $v_{1}, v_{2}$ and $v_{3}$ of the electrical circuit in figure 2 . Therefore, an electrical circuit is analogous to fluid flow system/plant, implying that we can model the process control of a bottle or sachet water plant by means of an electrical model.

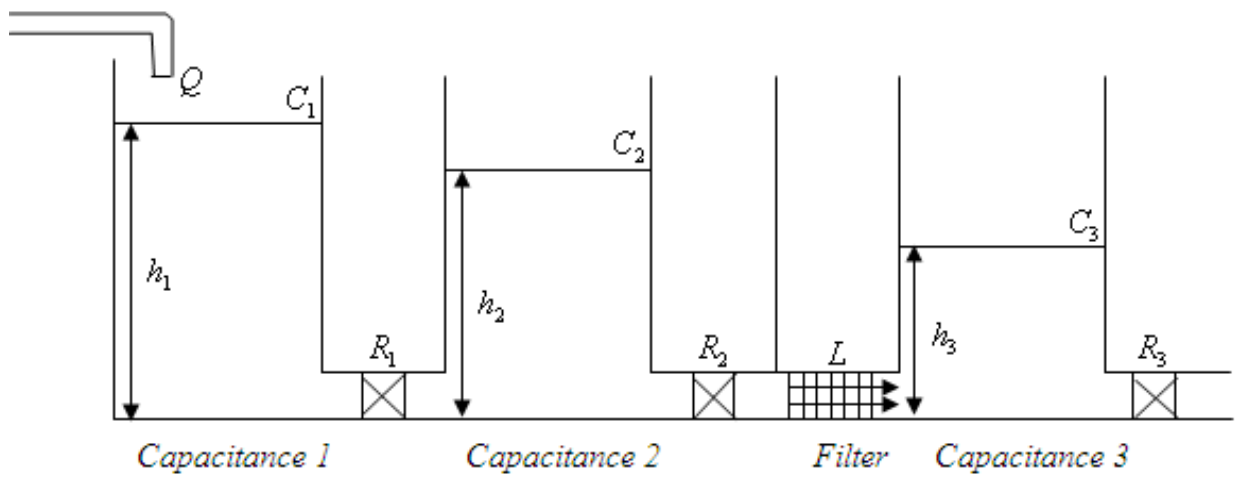

Figure 1: Coupled tank flow System (Ani, 2007).

The electrical circuit representation of the system is shown below:

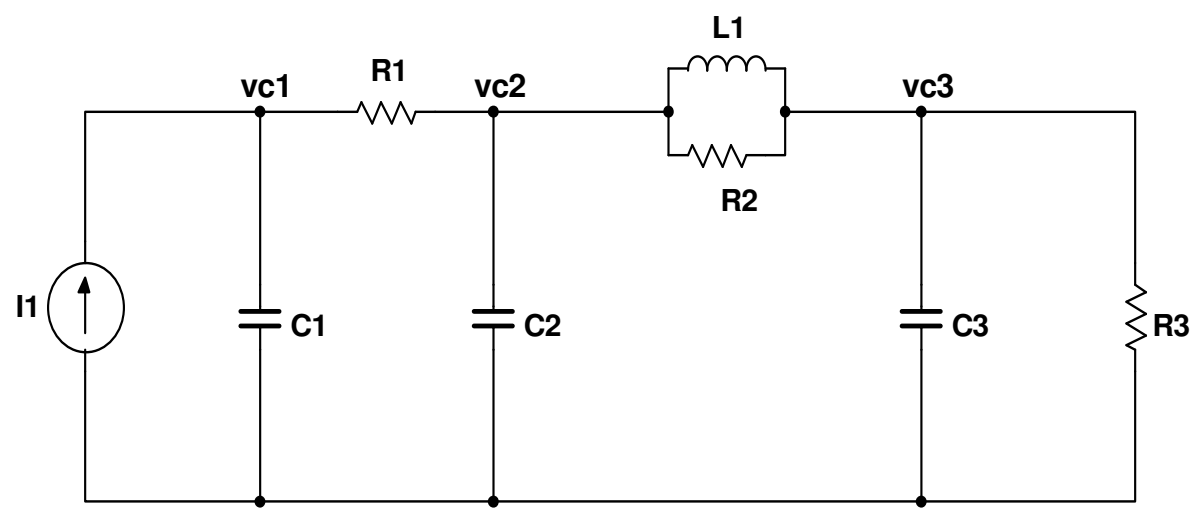

Figure 2: Electrical Circuit Equivalent (Ani, 2007).

\subsection{Mathematical Model}

Interconnection of the elements imposes constraints on the variation of system variables, and the convenient way of specifying these constraints is by a mathematical statement of the way in 
which the various through-variables are related and the way in which the various across-variables are related. This package of equations is a complete mathematical description of the system [12]. In this paper, a mathematical model describing the process control of bottle water plant is desirable. Such a model may be used to establish the limits of flow system, as well as evaluate all variables involved, leading to the optimization of the system parameters. Using principle of analogy, which states that two different physical systems can be described by the same mathematical model, these equations are converted into an Electrical circuit. This permits a generalization of ideas specific to a particular field in order that a broader understanding of a variety of apparently unrelated situations can be achieved. Using the method of analogy for which Kirchhoff's voltage and current laws are utilized, [4] obtain the state equation.

The network has four energy storage elements: three capacitors $C_{1}, C_{2}, C_{3}$, and an inductor $L$, and this network are specified by the voltage across the capacitors and current through the inductor. Since there are potential differences across the capacitors as well as current through the inductor, this electrical picture leads to ordinary differential equations.

The differential equations governing the behaviour of the network are [4]:

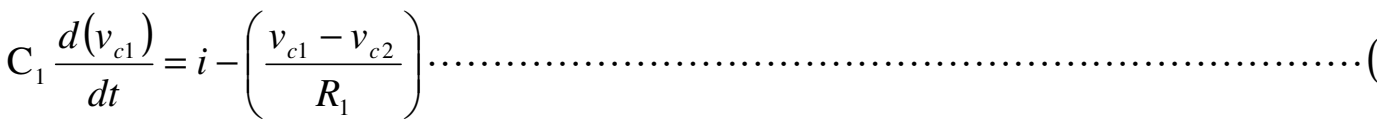

$$
\begin{aligned}
& C_{2} \frac{d\left(v_{c 2}\right)}{d t}=\left(\frac{v_{c 1}-v_{c 2}}{R_{1}}\right)-i \\
& L \frac{d\left(i_{1}\right)}{d t}=\frac{L}{R_{2}} \frac{d\left(v_{c 2}\right)}{d t}+v_{c 2}-v_{c 3} \\
& \mathrm{C}_{3} \frac{d\left(v_{c 3}\right)}{d t}=\frac{L}{R_{2}} \frac{d\left(v_{c 2}\right)}{d t}+v_{c 2}-\frac{v_{c 3}}{R_{3}}
\end{aligned}
$$

From equations (4-7) we have the process control equation in vector-matrix form, as [4]:

$$
\left[\begin{array}{l}
\dot{x}_{1} \\
\dot{x}_{2} \\
\dot{x}_{3} \\
\dot{x}_{4}
\end{array}\right]=\left[\begin{array}{cccc}
-\frac{1}{\mathrm{R}_{1} \mathrm{C}_{1}} & \frac{1}{\mathrm{R}_{1} \mathrm{C}_{1}} & 0 & 0 \\
\frac{1}{\mathrm{R}_{1} \mathrm{C}_{2}} & -\frac{1}{\mathrm{R}_{1} \mathrm{C}_{2}} & -\frac{1}{\mathrm{C}_{2}} & 0 \\
\frac{1}{\mathrm{R}_{1} R_{2} C_{2}} & -\frac{\left(L-R_{1} R_{2} C_{2}\right)}{R_{1} R_{2} C_{2} \mathrm{~L}} & -\frac{1}{R_{2} C_{2}} & -\frac{1}{\mathrm{~L}} \\
\frac{\mathrm{L}}{\mathrm{R}_{1} R_{2} C_{2} C_{3}} & -\frac{\left(\mathrm{L}-\mathrm{R}_{1} R_{2} C_{2}\right)}{\mathrm{R}_{1} R_{2} C_{2} C_{3}} & -\frac{L}{R_{2} C_{2} \mathrm{C}_{3}} & -\frac{1}{\mathrm{R}_{3} \mathrm{C}_{3}}
\end{array}\right]\left[\begin{array}{c}
x_{1} \\
x_{2} \\
x_{3} \\
x_{4}
\end{array}\right]+\left[\begin{array}{c}
\frac{1}{\mathrm{C}_{1}} \\
0 \\
0 \\
0
\end{array}\right][u] \cdots \cdots(8)
$$

The output equation is thus [4]: 
International Journal of Control Theory and Computer Modeling (IJCTCM) Vol.3, No.1, January 2013

$$
y=\left[\begin{array}{llll}
0 & 0 & 0 & 1
\end{array}\right]\left[\begin{array}{l}
x_{1} \\
x_{2} \\
x_{3} \\
x_{4}
\end{array}\right]
$$

Where

The Analogous components and variables are thus:

$i_{i}=Q_{i}$ (Input current; water flow into the process).

$i_{o}=Q_{o}$ (Output current; water flow from the process).

$C_{1}=($ Capacitance of capacitor 1 ; Capacity of tank 1 (sand treatment tank)).

$C_{2}=($ Capacitance of capacitor 2; Capacity of tank 2 (carbon treatment tank)).

$L=$ (Inductance of the inductor; filteration of the filter).

$C_{3}=($ Capacitance of capacitor 3; Capacity of tank 3 (Treated water tank)).

$v_{c 1}=h_{1}($ voltage across capacitor 1 ; water level of tank 1$)$.

$v_{c 2}=h_{2}$ (voltage across capacitor 2; water level of tank 2).

$v_{c 3}=h_{3}$ (voltage across capacitor 3; water level of tank 3).

$i_{1}=Q_{1}$ (flow of current through the inductor; rate of water flow through the filter).

$R_{1}=($ Resistance of the resistor 1 ; Restriction of pipe 1$)$.

$R_{2}=($ Resistance of the resistor 2; Restriction of pipe 2).

$R_{3}=($ Resistance of the resistor 3; Restriction of pipe 3).

From the model equation above, output $y$ depends on the state equation $x$ on $\quad x_{4}$ i.e. $y=x_{4}$. Therefore, $x$ and $y$ are dependent variables to be simulated.

The equation to be solved is:

$\dot{x}=A^{*} x+B^{*} u$

$y=C x$ 
The above equations contain all that we need to know about the theory of process control (flow) in a water processing plant that is in study. Solving the time domain $\dot{X}(t)=A x(t)+B u(t)$ and $Y(t)=C x(t)+D u(t)$ while $\mathrm{D}=0$ using Ordinary Differential Equation (ODE 45) of MATLAB Software.

\subsection{Simulation of the Model Equation using MATLAB.}

A program was developed to compute and study the effect of the state variables on the system during transient state. To determine the conditions that must exist for the system to work efficiently, trial values for the various parameters of the process control model were taken to simulate the process of water flow in the system. More than 150 trial simulations were conducted and the computed variables were picked and presented in this report.

Each group of simulation had a specific scenario in which a parameter was varied while the others were kept constant. The parameters, the values of which were varied include Resistance, Capacitance and Inductance. The variables $\left(v_{c 1}, v_{c 2}, i, v_{c 3}\right)$ representing the responses (water levels) of individual sections of the process were tabulated.

\subsection{Results}

The results of the simulation in tabular form are given below:

Table 1: Table of values with $R_{1}$ Varied while other parameters were kept constant

\begin{tabular}{|c|c|c|c|c|c|c|c|c|c|c|}
\hline$R_{1}$ & $R_{2}$ & $R_{3}$ & $L$ & $C_{1}$ & $C_{2}$ & $C_{3}$ & $v_{c 1}$ & $v_{c 2}$ & $i$ & $v_{c 3}$ \\
\hline 0.1 & 0.9 & 9.0 & 9.0 & $9 \mathrm{e}-03$ & $9 \mathrm{e}-03$ & $1900 \mathrm{e}-03$ & 1.0232 & 0.9237 & 0.9904 & 4.8779 \\
\hline 0.3 & 0.9 & 9.0 & 9.0 & $9 \mathrm{e}-03$ & $9 \mathrm{e}-03$ & $1900 \mathrm{e}-03$ & 1.2206 & 0.9222 & 0.9895 & 4.8698 \\
\hline 0.5 & 0.9 & 9.0 & 9.0 & $9 \mathrm{e}-03$ & $9 \mathrm{e}-03$ & $1900 \mathrm{e}-03$ & 1.4168 & 0.9200 & 0.9878 & 4.8577 \\
\hline 0.7 & 0.9 & 9.0 & 9.0 & $9 \mathrm{e}-03$ & $9 \mathrm{e}-03$ & $1900 \mathrm{e}-03$ & 1.6121 & 0.9175 & 0.9858 & 4.8442 \\
\hline 0.9 & 0.9 & 9.0 & 9.0 & $9 \mathrm{e}-03$ & $9 \mathrm{e}-03$ & $1900 \mathrm{e}-03$ & 1.8055 & 0.9142 & 0.9830 & 4.8269 \\
\hline
\end{tabular}

Table 2: Table of values with $R_{2}$ Varied while other parameters were kept constant

\begin{tabular}{|l|l|l|l|l|l|l|l|l|l|l|}
\hline$R_{2}$ & $R_{1}$ & $R_{3}$ & $L$ & $C_{1}$ & $C_{2}$ & $C_{3}$ & $v_{c 1}$ & $v_{c 2}$ & $i$ & $v_{c 3}$ \\
\hline 0.1 & 0.9 & 9.0 & 9.0 & $9 \mathrm{e}-03$ & $9 \mathrm{e}-03$ & $1900 \mathrm{e}-03$ & 1.0042 & 0.1046 & 0.9991 & 4.9362 \\
\hline 0.3 & 0.9 & 9.0 & 9.0 & $9 \mathrm{e}-03$ & $9 \mathrm{e}-03$ & $1900 \mathrm{e}-03$ & 1.2108 & 0.3122 & 0.9971 & 4.9184 \\
\hline 0.5 & 0.9 & 9.0 & 9.0 & $9 \mathrm{e}-03$ & $9 \mathrm{e}-03$ & $1900 \mathrm{e}-03$ & 1.4144 & 0.5171 & 0.9945 & 4.8975 \\
\hline 0.7 & 0.9 & 9.0 & 9.0 & $9 \mathrm{e}-03$ & $9 \mathrm{e}-03$ & $1900 \mathrm{e}-03$ & 1.6133 & 0.7183 & 0.9901 & 4.8683 \\
\hline 0.9 & 0.9 & 9.0 & 9.0 & $9 \mathrm{e}-03$ & $9 \mathrm{e}-03$ & $1900 \mathrm{e}-03$ & 1.8055 & 0.9142 & 0.9830 & 4.8269 \\
\hline
\end{tabular}

Table 3: Table of values with $R_{3}$ Varied while other parameters were kept constant

\begin{tabular}{|l|l|l|l|l|l|l|l|l|l|l|}
\hline$R_{3}$ & $R_{1}$ & $R_{2}$ & $L$ & $C_{1}$ & $C_{2}$ & $C_{3}$ & $v_{c 1}$ & $v_{c 2}$ & $i$ & $v_{c 3}$ \\
\hline 1.0 & 0.9 & 0.9 & 9.0 & $9 \mathrm{e}-03$ & $9 \mathrm{e}-03$ & $1900 \mathrm{e}-03$ & 1.8051 & 0.9138 & 0.9832 & 4.6573 \\
\hline 3.0 & 0.9 & 0.9 & 9.0 & $9 \mathrm{e}-03$ & $9 \mathrm{e}-03$ & $1900 \mathrm{e}-03$ & 1.8054 & 0.9141 & 0.9830 & 4.7839 \\
\hline 5.0 & 0.9 & 0.9 & 9.0 & $9 \mathrm{e}-03$ & $9 \mathrm{e}-03$ & $1900 \mathrm{e}-03$ & 1.8055 & 0.9142 & 0.9830 & 4.8096 \\
\hline 7.0 & 0.9 & 0.9 & 9.0 & $9 \mathrm{e}-03$ & $9 \mathrm{e}-03$ & $1900 \mathrm{e}-03$ & 1.8055 & 0.9142 & 0.9830 & 4.8207 \\
\hline 9.0 & 0.9 & 0.9 & 9.0 & $9 \mathrm{e}-03$ & $9 \mathrm{e}-03$ & $1900 \mathrm{e}-03$ & 1.8055 & 0.9142 & 0.9830 & 4.8269 \\
\hline
\end{tabular}


International Journal of Control Theory and Computer Modeling (IJCTCM) Vol.3, No.1, January 2013

Table 4: Table of values with $L$ Varied while other parameters were kept constant

\begin{tabular}{|l|l|l|l|l|l|l|l|l|l|l|}
\hline$L$ & $R_{1}$ & $R_{2}$ & $R_{3}$ & $C_{1}$ & $C_{2}$ & $C_{3}$ & $v_{c 1}$ & $v_{c 2}$ & $i$ & $v_{c 3}$ \\
\hline 1.0 & 0.9 & 0.9 & 9.0 & $9 \mathrm{e}-03$ & $9 \mathrm{e}-03$ & $1900 \mathrm{e}-03$ & 1.7680 & 0.8714 & 0.9949 & 0.5428 \\
\hline 3.0 & 0.9 & 0.9 & 9.0 & $9 \mathrm{e}-03$ & $9 \mathrm{e}-03$ & $1900 \mathrm{e}-03$ & 1.7959 & 0.9033 & 0.9860 & 1.6138 \\
\hline 5.0 & 0.9 & 0.9 & 9.0 & $9 \mathrm{e}-03$ & $9 \mathrm{e}-03$ & $1900 \mathrm{e}-03$ & 1.8018 & 0.9099 & 0.9843 & 2.6851 \\
\hline 7.0 & 0.9 & 0.9 & 9.0 & $9 \mathrm{e}-03$ & $9 \mathrm{e}-03$ & $1900 \mathrm{e}-03$ & 1.8043 & 0.9127 & 0.9835 & 3.7562 \\
\hline 9.0 & 0.9 & 0.9 & 9.0 & $9 \mathrm{e}-03$ & $9 \mathrm{e}-03$ & $1900 \mathrm{e}-03$ & 1.8055 & 0.9142 & 0.9830 & 4.8269 \\
\hline
\end{tabular}

Table 5: Table of values with $C_{1}$ Varied while other parameters were kept constant

\begin{tabular}{|l|l|l|l|l|l|l|l|l|l|l|}
\hline$C_{1}$ & $C_{2}$ & $C_{3}$ & $L$ & $R_{1}$ & $R_{2}$ & $R_{3}$ & $v_{c 1}$ & $v_{c 2}$ & $i$ & $v_{c 3}$ \\
\hline $1 \mathrm{e}-03$ & $9 \mathrm{e}-03$ & $1900 \mathrm{e}-03$ & 9.0 & 0.9 & 0.9 & 9.0 & 1.8313 & 0.9316 & 0.9960 & 4.9213 \\
\hline $3 \mathrm{e}-03$ & $9 \mathrm{e}-03$ & $1900 \mathrm{e}-03$ & 9.0 & 0.9 & 0.9 & 9.0 & 1.8282 & 0.9293 & 0.9951 & 4.9085 \\
\hline $5 \mathrm{e}-03$ & $9 \mathrm{e}-03$ & $1900 \mathrm{e}-03$ & 9.0 & 0.9 & 0.9 & 9.0 & 1.8241 & 0.9263 & 0.9933 & 4.8919 \\
\hline $7 \mathrm{e}-03$ & $9 \mathrm{e}-03$ & $1900 \mathrm{e}-03$ & 9.0 & 0.9 & 0.9 & 9.0 & 1.8170 & 0.9215 & 0.9896 & 4.8660 \\
\hline $9 \mathrm{e}-03$ & $9 \mathrm{e}-03$ & $1900 \mathrm{e}-03$ & 9.0 & 0.9 & 0.9 & 9.0 & 1.8055 & 0.9142 & 0.9830 & 4.8269 \\
\hline
\end{tabular}

Table 6: Table of values with $C_{2}$ Varied while other parameters were kept constant

\begin{tabular}{|l|l|l|l|l|l|l|l|l|l|l|}
\hline$C_{2}$ & $C_{1}$ & $C_{3}$ & $L$ & $R_{1}$ & $R_{2}$ & $R_{3}$ & $v_{c 1}$ & $v_{c 2}$ & $i$ & $v_{c 3}$ \\
\hline $1 \mathrm{e}-03$ & $9 \mathrm{e}-03$ & $1900 \mathrm{e}-03$ & 9.0 & 0.9 & 0.9 & 9.0 & 1.8211 & 0.9265 & 0.9935 & 4.8929 \\
\hline $3 \mathrm{e}-03$ & $9 \mathrm{e}-03$ & $1900 \mathrm{e}-03$ & 9.0 & 0.9 & 0.9 & 9.0 & 1.8185 & 0.9243 & 0.9918 & 4.8810 \\
\hline $5 \mathrm{e}-03$ & $9 \mathrm{e}-03$ & $1900 \mathrm{e}-03$ & 9.0 & 0.9 & 0.9 & 9.0 & 1.8143 & 0.9212 & 0.9891 & 4.8641 \\
\hline $7 \mathrm{e}-03$ & $9 \mathrm{e}-03$ & $1900 \mathrm{e}-03$ & 9.0 & 0.9 & 0.9 & 9.0 & 1.8106 & 0.9182 & 0.9866 & 4.8479 \\
\hline $9 \mathrm{e}-03$ & $9 \mathrm{e}-03$ & $1900 \mathrm{e}-03$ & 9.0 & 0.9 & 0.9 & 9.0 & 1.8055 & 0.9142 & 0.9830 & 4.8269 \\
\hline
\end{tabular}

Table 7: Table of values with $C_{3}$ Varied while other parameters were kept constant

\begin{tabular}{|l|l|l|l|l|l|l|l|l|l|l|}
\hline$C_{3}$ & $C_{1}$ & $C_{2}$ & $L$ & $R_{1}$ & $R_{2}$ & $R_{3}$ & $v_{c 1}$ & $v_{c 2}$ & $i$ & $v_{c 3}$ \\
\hline $1000 \mathrm{e}-03$ & $9 \mathrm{e}-03$ & $9 \mathrm{e}-03$ & 9.0 & 0.9 & 0.9 & 9.0 & 1.8287 & 0.9408 & 0.9753 & 9.4005 \\
\hline $1300 \mathrm{e}-03$ & $9 \mathrm{e}-03$ & $9 \mathrm{e}-03$ & 9.0 & 0.9 & 0.9 & 9.0 & 1.8173 & 0.9278 & 0.9791 & 7.1447 \\
\hline $1500 \mathrm{e}-03$ & $9 \mathrm{e}-03$ & $9 \mathrm{e}-03$ & 9.0 & 0.9 & 0.9 & 9.0 & 1.8124 & 0.9221 & 0.9807 & 6.1590 \\
\hline $1700 \mathrm{e}-03$ & $9 \mathrm{e}-03$ & $9 \mathrm{e}-03$ & 9.0 & 0.9 & 0.9 & 9.0 & 1.8085 & 0.9177 & 0.9820 & 5.4122 \\
\hline $1900 \mathrm{e}-03$ & $9 \mathrm{e}-03$ & $9 \mathrm{e}-03$ & 9.0 & 0.9 & 0.9 & 9.0 & 1.8055 & 0.9142 & 0.9830 & 4.8269 \\
\hline
\end{tabular}

\subsection{The Analysis of the Results of the Simulation.}

The analysis of the results of the seven (7) simulations made by varying the values of the parameters of the model, one after the other, and the interpretations of the observed values of the variables $\left(v_{c 1}, v_{c 2}, i\right.$, and $\left.v_{c 3}\right)$ as related to the rate of water flow, are given below:

\subsubsection{First Simulation}

An increase in the Restriction $\left(R_{1}\right)$ to flow between tanks 1 and 2 (see plant), while keeping the other parameters constant, caused reasonable increase in the water level of tank 1, while water 
levels of tanks 2, 3 decreased and flow $\left(i_{1}\right)$ through the filter $(L)$ also decreased as shown in table 1. In essence, this may be regarded as attempting to fine tune the process so as to influence the overall rate of water flow into the bottle (since varying $R_{1}$ has an effect on the water levels of tanks 1, 2, 3 and water flow $\left(i_{1}\right)$ through the filter).

\subsubsection{Second Simulation}

An increase in the restriction $\left(R_{2}\right)$ of water flow between tank 2 and filter (while keeping the other parameters constant) caused reasonable increase in water levels of tanks 1,2 , with tank 2 affected most, while the flow of water through the filter and the water level of tank 3 decreased as shown in table 2 . This could be interpreted as meaning that an increase in $R_{2}$ decreased the water levels in tank 3, thereby decreasing the water flow into the bottle. As stated above, this can also be interpreted as attempting to fine tune the process so as to influence the overall rate of water flow into the bottle.

\subsubsection{Third simulation}

An increase in the restriction, $\left(R_{3}\right)$ (while keeping the other parameters constant) caused an increase in the water levels of all the tanks 1,2, 3 [minimal changes (increase) in water levels of tanks 1, 2 and reasonable changes (increase) in water level of tank 3], while flow of water through the filter decreased as shown in table 3 . The essence of this is to fine tune the process so as to get the right flow of water from the plant into the bottle. More specifically, this parameter is used to control the rate of water flow into the bottle.

\subsubsection{Fourth simulation}

Here varying $L$ (the inductance) and keeping other parameters constant caused minimal changes (increase) in the water levels of all the tanks $1,2,3$, while the flow $\left(i_{1}\right)$ of water through the filter decreased showing that at high filtration, the flow of water through the filter lessened (decreased) as shown in table 4. This could be interpreted as indicating that at high filtration (indicating increase in number of wound string of the conductor), the flow $\left(i_{1}\right)$ of water through the filter decreases, thereby affecting the overall output of water flow into the bottles.

\subsubsection{Fifth simulation}

Varying $C_{1}$ (increasing the capacity of tank 1) and keeping other parameters constant caused changes (decrease) in all the water levels of tanks 1,2,3 and flow $\left(i_{1}\right)$ through the filter as shown in table 5. The essence of this variation is to study the effects of $C_{1}$ (capacity of tank 1 ) on the process (flow of water into the bottle) and its interaction with the other parameters of the model. In this circumstance, the increase in the value of $C_{1}$ could be interpreted as decreasing the rate of water flow into the bottles.

\subsubsection{Sixth simulation}

Varying $C_{2}$ (capacity of tank 2) and keeping other parameters constant caused changes (decrease) in all the water levels of tanks 1,2,3 and flow $\left(i_{1}\right)$ through the filter as shown in table 
6. This is also to study the effects of $C_{2}$ (capacity of tank 2) on the process (flow of water into the bottle) and its interaction with the other parameters of the model.

\subsubsection{Seventh simulation}

Varying $C_{3}$ (capacity of tank 3) and keeping other parameters constant caused changes (decrease) in all the water levels of tanks 1, 2, 3, while it caused an increase in flow $\left(i_{1}\right)$ through the filter, showing that any variation of the capacity of tank 3 affects all the water levels of tanks $1,2,3$ (decrease) and flow $\left(i_{1}\right)$ of water through the filter (increase) as shown in table 7 . The essence of this variation is to study the effects of $C_{3}$ (capacity of tank 3 ) to the process (flow of water into the bottle) and its interaction with other parameters of the model.

\subsection{OBSERVATIONS}

\subsubsection{The connecting pipes:}

We observed that varying the restriction of the connecting pipes implies that either the radius (size) of the pipe is decreased/increased or the length of the pipe is increased/decreased which significantly influences the flow of water through the filter, but caused varying effects on the water levels in all the tanks. It is an attempt to fine tune the process so as to influence the rate of water flow (to get the right water flow from the plant).

\subsubsection{The capacity of the tanks:}

We observed that varying the value of the capacities (capacitances) of any of the tanks in the process significantly influences (decreases/increases) the water levels in all the tanks, but caused varying effects on the flow of water through the filter. This implies that an increase in the value of $C$ (capacity of tank) decreases the water level $(h)$ in the tank and hence the rate of water flow in the process, while a decrease in the value of $C$ (capacity of tank) increases $h$ and hence the rate of water flow in the process depending on the type and size of pipe used which must obey the relations stated in equations $4-7$.

\subsubsection{Inductance of the filter:}

We observed that varying the inductance ( $L$ ) of the filter influences the water levels in all the tanks, but caused changes (decrease) in the flow of water through the filter, implying that an increase in the inductance $(L)$ (number of wound string on the filter cartridge) increases filteration. An increase in filteration tends to decrease the flow of water through the filter, and this in turn tends to influence the rate of water flow in the process.

\section{CONCLUSIONS}

This work presents an electrical model for studying the process behaviour of bottled water production plant. In this model, the mechanical components of the plant such as the connecting pipes, the water tanks and the water filter were represented by resistors, capacitors and an inductor, respectively. A state equation was developed as a mathematical model of the electrical circuit. In this equation, resistors, capacitors and inductor, representing the restriction of the pipes, the capacity of the tanks and the filtration of the filter, respectively, were used as variable parameters to generate the state variables (voltages/potential drops and current in the electrical 
model (circuit)) of the state equation (mathematical model). This mathematical model was used to simulate the effects of varying the electrical parameters $(R, C$, and $L)$ on the state variables (voltage, $v$, and current, $i$ ) representing the restriction (as function of the diameter and length) of the connecting pipes, the water levels $(h)$ in the water tanks and the filtration of the water filter, respectively. From the Analysis, it was observed that by varying the electrical parameters (resistors, capacitors, inductor), it is possible to study the way the manipulation of equivalent parameters of the analogous mechanical components (the connecting pipes, the water tanks and the water filter) of the sachet water plant could influence the rate of water flow in the production process of bottled water. This model describes the natural process, yields reproducible results when solved with simulation software and, consequently, used for predictive purposes in bottled water production plants.

\section{REFERENCES}

[1]. Nemeth. H (2004) Nonlinear modeling and control for a Mechatronic Protection valve. Theses of Ph.D dissertation, Budapest University of Technology and Economics, Hungary, pg 4-6,

[2]. Spirax Sarco - learning centre: An Introduction to Controls. www.spiraxsarco.com/learn/html/5_1_01.htm

[3]. Neelamkavil. F. (1987) Computer Simulation and Modeling. John Wiley and sons Ltd., New York, NY, pp.22-39,

[4]. Ani, V.A. (2007). Simulation of a Sachet Water Processing Plant Using an Analogous Electrical Model. (M.Sc thesis) Department of Electronic Engineering, University of Nigeria Nsukka

[5]. Skibitzke. E.H. (1960) Electronic Computer as an aid to the Analysis of Hydrologic Problems: Gentbrugge, Belgium, Internat.Assoc.Sci.Hydrology, Comm.Subterranean waters, Pub.52, pg.347358.

[6]. Walton, C.W. and Prickett, A.T. (1963) Hydrogeologic Electric Analog Computer: Am.Soc.Civil Engineers, Jour.Hydraulics Div., V.89, no.HY6, Proc.Paper 3695, pg 67-91.

[7]. Patten, E.P (1965) Design, Construction, and use of electric analog models in A.L.wood and K.R.Gabrysch. Analog model study of ground water in the Houston District, Texas: Texas water Comm.Bull.6508, pg 41-60.

[8]. Hardt, F.W. (1971) Hydrologic Analysis of Mojave River Basin, California, using Electric Analog Model, U.S.Geol.Survey Open-file rept., 97.

[9]. Dorf, C.Richard and.Bishop, H.Robert (1998) "Modern Control Systems". Addison-Wesley Longman, Inc., New York, $8^{\text {th }}$ edition, pg 38,

[10]. Ord-Smith, R.J and Stephenson, J. (1975) Computer Simulation of Continuous Systems. Cambridge University Press, London.

[11]. Nzeako. A.N (2006) “Control Engineering” Lecture note on ECE 451, Department of Electronic Engineering, University of Nigeria, Nsukka].

[12]. Basualdo, M.S. (1990) Ph. D Thesis “Dynamic and Control of Distillation Columns”, INTECCONICET-UNL,

[13]. Douglas M.Considine. Process/Industrial Instruments \& Controls Handbook. Mc Graw-Hill, Inc., USA. $4^{\text {th }}$ edition. 1993.

[14]. Dynamic Simulation of Chemical Process as a Tool to Teach "The Real Problem" of Identification and Control. http://fie.engrng.pitt.edu/fie95/3b3/3b31/3b31.htm

[15]. F.A.Abott. Ordinary Level Physics. Heinemann Educational Books London. 1979.

\section{APPENDIX}

Expressions for determining the parameters of the system.

\section{Derivation of Resistance R.}

From Ohm's law 
International Journal of Control Theory and Computer Modeling (IJCTCM) Vol.3, No.1, January 2013

$$
R=\frac{v}{i}
$$

Also, Resistivity for material that obeys Ohm's law is given as

$$
\rho=\frac{E}{J}
$$

where

$$
\begin{aligned}
& E=\text { Electric field of a point, } \\
& J=\text { the current density }
\end{aligned}
$$

If total current in the material is $i$ and potential difference between plate is $v$. Also assume the material is of uniform cross-sectional area $A$ and length $l$.

$$
\begin{aligned}
& v=E l \\
& i=J A
\end{aligned}
$$

Substituting equation (A3) and (A4) into equation (A2)

$$
\begin{aligned}
& \rho=\left(\frac{v}{l}\right) \div\left(\frac{i}{A}\right) \\
& \frac{v}{l}=\frac{\rho i}{A} \\
& \frac{v}{i}=\frac{\rho l}{A}=R
\end{aligned}
$$

$\therefore R=\frac{\rho l}{A}[13],[14]$.

Where

$\rho=$ Resistivity of material

$A=$ cross-sectional Area

$l=$ length of material

$i=$ current

$v=$ potential difference

$R=$ Resistance

\section{Derivation of Inductance L.}

$$
L=\frac{v}{i}
$$


International Journal of Control Theory and Computer Modeling (IJCTCM) Vol.3, No.1, January 2013

$v=$ induced $e m f$

Induced emf $\varepsilon=\frac{N \Delta \phi}{\Delta t}$

since $i$ vary with time.

$$
\begin{gathered}
i=\frac{\Delta i}{\Delta t} . \\
\therefore L=\frac{N \Delta \phi}{\Delta t} \times \frac{\Delta t}{\Delta i} \\
L=\frac{N \Delta \phi}{\Delta i} \text {----------self induction }
\end{gathered}
$$

But flux $\Delta \phi=B A \cos \phi$

Since $\phi=0$

$$
L=\frac{N B A}{i} \text {-------------------------------------------------------equation }
$$

From Bio-savart law

$$
B=\frac{N i \mu_{o} \mu_{r}}{l}
$$

Substituting the above (equation (A7)) into equation (A6)

$$
L=\frac{N\left(N i \mu_{o} \mu_{r}\right) A}{i l}=\frac{N^{2} \mu_{o} \mu_{r} A}{l}
$$

Where

$$
\begin{aligned}
& l=2 \pi d \\
& \therefore L=\frac{N^{2} \mu_{o} \mu_{r} A}{2 \pi d}[15] .
\end{aligned}
$$

Where

$$
\begin{aligned}
& \mu_{o}=\text { Permeability of free space } \\
& \mu_{r}=\text { Relative Permeability of material }
\end{aligned}
$$


International Journal of Control Theory and Computer Modeling (IJCTCM) Vol.3, No.1, January 2013

$$
\begin{aligned}
N & =\text { Number of turns } \\
l & =\text { Mean length of coil } \\
A & =\text { Surface area density } \\
& =4 \pi r^{2} \\
B & =\text { Magnetic field }
\end{aligned}
$$

\section{Derivation of Capacitance C.}

$$
\begin{gathered}
C=\frac{Q}{v} \\
v=E_{1} t+E_{2}(d-t)
\end{gathered}
$$

Where $E_{1}=\frac{D}{\varepsilon_{o} \varepsilon_{r}}$ (in medium); $E_{2}=\frac{D}{\varepsilon_{o}}$ (in air).

Flux density $D=\frac{Q}{A}$

$$
\begin{aligned}
& v=\frac{D}{\varepsilon_{o} \varepsilon_{r}} t+\frac{D}{\varepsilon_{o}}(d-t)=\frac{D}{\varepsilon_{o}}\left(\frac{t}{\varepsilon_{r}}+d-t\right) \\
& v=\frac{D}{\varepsilon_{o}}\left(\frac{t}{\varepsilon_{r}}+d-t\right) \\
& Q=D A \\
& C=\frac{Q}{v}=\frac{D}{\frac{D}{\varepsilon_{o}}\left(\frac{t}{\varepsilon_{r}}+d-t\right)}=D A \times \frac{\varepsilon_{o}}{D}\left(\frac{1}{d-\left(t-\frac{t}{\varepsilon_{r}}\right)}\right) \\
& C=\frac{\varepsilon_{o} A}{\left[d-\left(t-\frac{t}{\varepsilon_{r}}\right)\right]}
\end{aligned}
$$$$
\therefore C=\frac{Q}{v}=\frac{\varepsilon_{o} A}{\left[d-\left(t-\frac{t}{\varepsilon_{r}}\right)\right]}
$$

The above equation is formula for a capacitance having dielectric partly air and partly some other medium [15]. 
$C=\frac{Q}{v}=\frac{\varepsilon_{o} A}{d}$

The above equation is formula for a capacitance having only air as dielectric.

Where

$E=$ Electric intensity

$Q=$ Electric charge

$t=$ Thickness of the parallel plate

$D=$ Flux density

$\varepsilon_{r}=$ Relative Permittivity of the material

$\varepsilon_{o}=$ Permittivity of air/vacuum

$d=$ Height difference between the positive $\&$ negative side.

$A=$ Area of the parallel plate

$C=$ Capacitance of the capacitor

\section{Capacitance:}

$$
C=\frac{Q}{v}=\frac{\varepsilon_{o} A}{\left[d-\left(t-\frac{t}{\varepsilon_{r}}\right)\right]}
$$

The above equation is formula for a capacitance having dielectric partly air and partly some other medium.

$$
C=\frac{Q}{v}=\frac{\varepsilon_{o} A}{d}
$$

The above equation is formula for a capacitance having only air as dielectric.

Where

$t=$ Thickness of the parallel plate (thickness of the sand $/$ carbon layer) $=41$ inches for sand \& 45 inches for carbon.

$\varepsilon_{r}=$ Relative Permittivity of the material (relative permittivity of sand WRT water / relative permittivity of carbon WRT water).

$\varepsilon_{o}=$ Permittivity of air/vacuum $=\left(8.85 \times 10^{-12}\right)$

$d=$ Height difference between the positive $\&$ negative side (distance from top to bottom of the tank (total length) $=61.5$.

$r=$ radius of the parallel plate (radius of the tank) $=$ varied.

$A=$ Area of the parallel plate (Area of the tank) $=4 \pi r^{2}$.

$C=$ Capacitance of the capacitor (Capacitance of the tank)

Relative Permittivity $\varepsilon_{r}=\frac{\left(\varepsilon_{k}\right)}{\varepsilon_{o}}$

Where 
$\varepsilon_{k}=$ Permittivity dielectric constant

$\varepsilon_{o}=$ Permittivity of vacuum.

The relative Permittivity of sand with respect to water is thus:

$$
\begin{aligned}
\mathcal{E}_{r(s w)}= & \frac{\frac{\varepsilon_{k s}}{\varepsilon_{o}}}{\frac{\varepsilon_{k w}}{\varepsilon_{o}}}=\frac{\varepsilon_{k s}}{\varepsilon_{o}} \times \frac{\varepsilon_{o}}{\varepsilon_{k w}} \\
\mathcal{E}_{r(s w)} & =\frac{\varepsilon_{k s}}{\varepsilon_{k w}}
\end{aligned}
$$

where

$\varepsilon_{r(s w)}=$ Relative permittivity of sand with respect to water

$\varepsilon_{k s}=$ Permittivity dielectric constant of sand.

$\varepsilon_{k w}=$ Permittivity dielectric constant of water.

The relative Permittivity of carbon with respect to water is thus:

$$
\begin{aligned}
& \varepsilon_{r(c w)}=\frac{\frac{\varepsilon_{k c}}{\varepsilon_{o}}}{\frac{\varepsilon_{k w}}{\varepsilon_{o}}}=\frac{\varepsilon_{k c}}{\varepsilon_{o}} \times \frac{\varepsilon_{o}}{\varepsilon_{k w}} \\
& \varepsilon_{r(c w)}=\frac{\varepsilon_{k c}}{\varepsilon_{k w}} \\
& \varepsilon_{r(c w)}=\text { Relative permittivity of carbon with respect to water. } \\
& \varepsilon_{k c}=\text { Permittivity dielectric constant of carbon. } \\
& \varepsilon_{k w}=\text { Permittivity dielectric constant of water. }
\end{aligned}
$$

\section{Author's Biography}

Mr Vincent Anayochukwu Ani is a Ph.D candidate at the Department of Electronic Engineering, University of Nigeria, Nsukka [UNN], Nigeria, where he also received his M.Sc Degree in Control Engineering. He is a member of a Team of Researchers from three universities, [University of Nigeria, Nsukka (UNN), Cross River University of Technology (CRUTECH) and Ambrose Alli University, Ekpoma (AAU)] on Modeling, Simulation and Optimization. e-mail: vincent_ani@yahoo.com

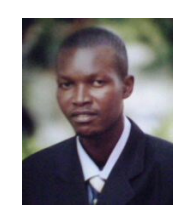

